DE

M E D I C I N A

T R O P I C A L

$\mathrm{DE}$

SÃO PAULO

JOURNAL OF THE SÃO PAULO INSTITUTE OF TROPICAL MEDICINE

Universidade de São Paulo, Instituto de Medicina Tropical de São Paulo, Laboratório de Bacteriologia (LIM 54), São Paulo, São Paulo, Brazil

Correspondence to: Sânia Alves dos Santos

Universidade de São Paulo, Instituto de Medicina Tropical de São Paulo, Laboratório de Bacteriologia (LIM 54), Av. Dr. Enéas de Carvalho Aguiar, 500, $1^{\circ}$ andar, sala 107 , CEP 05403-000, São Paulo, SP, Brazil Tel: +55 113061-7029

E-mail: saniasan@usp.br

Received: 2 June 2017

Accepted: 7 November 2017

\section{HIF-1alpha and infectious diseases: a new frontier for the development of new therapies}

\author{
Sânia Alves dos Santos, Dahir Ramos de Andrade Júnior
}

\section{ABSTRACT}

The aim of this review is to show the significant role of HIF-1alpha in inflammatory and infectious diseases. Hypoxia is a physiological characteristic of a wide range of diseases from cancer to infection. Cellular hypoxia is sensed by oxygen-sensitive hydrolase enzymes, which control the protein stability of hypoxia-inducible factor alpha 1 (HIF-1alpha) transcription factors. When stabilized, HIF-1alpha binds with its cofactors to HIF-responsive elements (HREs) in the promoters of target genes to organize a broad ranging transcriptional program in response to the hypoxic environment. HIF-1alpha also plays a regulatory function in response to a diversity of molecular signals of infection and inflammation even under normoxic conditions. HIF-1alpha is stimulated by pro-inflammatory cytokines, growth factors and a wide range of infections. Its induction is a general element of the host response to infection. In this review, we also discuss recent advances in knowledge on HIF-1alpha and inflammatory responses, as well as its direct influence in infectious diseases caused by bacteria, virus, protozoan parasites and fungi.

KEYWORDS: HIF-1alpha. Hypoxia. Bacteria. Sepsis. Virus. Parasites. Fungi.

\section{CRITERIA FOR LITERATURE SEARCH}

Literature search was conducted to identify articles on the HIF-1alpha role in infectious diseases. The following search terms were entered into two electronic databases (Medline via PubMed and SciELO): HIF-1alpha (HIF), HIF and sepsis; HIF and bacteria; HIF and Pseudomonas; HIF and E.coli; HIF and S. aureus; HIF and Salmonella; HIF and virus; HIF and protozoan parasites; HIF and fungi and HIF and cancer, with language restriction for English language articles from 1995 to 2017. Reference lists of relevant studies were reviewed to identify additional studies not found by the initial search.

In the first part of the study, 130 articles that could be useful to this review work were found.

Three screening levels for eligibility were performed. The first screening level was performed using titles and abstracts, excluding references that did not contain information on HIF-1alpha and infectious diseases, did not discuss concepts on HIF-1alpha restricted to HIF expression in hypoxic environments. A second screening level, also based on titles and abstracts, was performed. This level was restricted to results of specific topics, such as: sepsis, bacteria, virus, protozoan parasites and fungi. The final screening level was performed using the full-text publications and identified studies with the information required to specific pathogens: Enterobacteriaceae sp, Escherichia coli, Chlamydia trachomatis, Pseudomonas aeruginosa, group A Streptococcus, Yersinia enterocolitica, Salmonella, Bartonella 
henselae, Shigella flexneri, Mycobacterium tuberculosis, Staphylococcus aureus, Helicobacter pylori, Hepatitis C virus, Human papillomaviruses, Toxoplasma gondii, Leishmania sp, Aspergillus fumigatus, Candida albicans, Histoplasma capsulatum and Coccidioides immitis.

Full text of publications that met all eligibility criteria underwent data extraction. After careful analysis, we chose 66 articles to make up the final database of the study.

\section{CONCEPTS ON HIF-1ALPHA}

Earth's atmosphere changed from an anoxic state to an oxygenated state two billion years ago. This event contributed to the biological diversification when oxygen was supplied as free energy for living creatures. Nowadays, all eukaryotes from simple yeasts to highly developed humans depend mainly on molecular oxygen ${ }^{1}$.

The transcription factor HIF-1alpha was first identified in $1995^{2}$ and, since its detection, it has been associated with several types of disease from cancer to infection. Cells under oxygen levels lower than physiological undertake a diversity of biological responses in order to adapt to these critical conditions. Hypoxic cells respond by increasing the expression of various genes that will help survival under these situations. The main cellular response manager to low oxygen levels is HIF-1alpha ${ }^{3,4}$. Upon hypoxia, cells react by increasing the expression of genes encoding proteins that facilitate oxygen supply (e.g., erythropoietin, VEGF) or improve anaerobic production of energy (e.g., glycolytic enzymes).

The importance of HIF-1alpha in mammalian development can be seen by noting that its absence is lethal for embryogenesis, in part because of defective vascularization. HIF-1alpha activation can have adaptive roles in a diversity of pathological conditions: HIF-1alpha allows revascularization after cardiac and cerebral ischemia, but it also favors tumor growth in hypoxic environments by promoting angiogenesis and metabolic adaptations to hypoxia ${ }^{5}$.

Another relevant finding is that HIF-1alpha pathway is present in almost all cell types and all higher eukaryotes ${ }^{6}$. HIF complex supports the expression of genes such as erythropoietin (EPO) by binding to hypoxia-responsive enhancer elements (HREs) ${ }^{7}$.

In humans, three different subunits, HIF-1alpha, HIF-2alpha, and HIF-3alpha have been recognized. Structurally related and close subunits share a unique $\mathrm{O}_{2}$-dependent degradation domain (ODDD). Central to the ODDD function are proline residues (two for HIF-1alpha and HIF-2alpha, and one for HIF-3alpha) ${ }^{8}$.

HIF-1alpha activity is closely regulated by oxygen- dependent control of the cell. In oxygenated states, HIF-1alpha is quickly degraded in an ubiquitin dependent way and its degradation is mediated by hydroxylation on Pro-402 and -564. A family of prolyl hydroxylases (PHDs) modifies the subunit HIF-1alpha, turning HIF into a target of its degradation. The proline hydroxylases that change HIF-1alpha are also $\mathrm{Fe}^{2+}$-dependent and oxygendependent. PHDs use molecular oxygen to hydroxylate specific proline residues placed in the conserved motif LxxLAP. The produced hydroxyproline residues are recognized by the von Hippel-Lindau (VHL) tumor suppressor protein that is a component of a multiprotein E3 ubiquitin ligase complex. HIF-1alpha is not degraded under hypoxic conditions, and the stable protein dimerizes with HIF-1alpha constitutively expressed in the nucleus. The active HIF-1alpha heterodimer binds to related promoter elements and also to DNA for activation of its target genes. This event leads to expression of hypoxia-inducible proteins such as vascular endothelial growth factor, erythropoietin, and nitric oxide synthetase ${ }^{5,9,10}$. Expression and stability of HIF-1alpha under normoxic conditions can also be regulated by main signal transduction pathways induced by growth factors and cytokines, including those related to PI3K and ERK/ MAPK ${ }^{9,10}$.

HIF acts on late cell death induced by hypoxia. HIF-1alpha activates late death in cortical neurons by a p53-dependent pathway, thus defining an important regulating element of ischemic cell death ${ }^{7}$.

The hypoxic response is important for the function of tissue macrophages and infiltrating neutrophils that find low $\mathrm{O}_{2}$ pressure in infected tissues. HIF-1alpha was also suggested to promote expression of inflammatory cytokines in macrophages stimulated with LPS to induce cytokines production through the regulation of NF-kB. Some studies show that transcriptional activation of HIF-1alpha gene by IKK $\beta$-responsive NF- $\mathrm{KB}$ is of significant value under important pathological conditions ex vivo and in vivo. Both, macrophages infected with bacteria and mice exposed to hypoxia reveal a prominent HIF-1alpha induction defect upon loss of IKK $\beta$. NF- $\kappa B$ is also a hypoxia-regulated transcription factor that controls HIF-1alpha expression and serves as a main regulator of the hypoxic response. NF- $\mathrm{KB}$ can enhance glycolytic energy metabolism and production of angiogenic factors by controlling HIF-1alpha activation in macrophages during microbial infections, besides its well-established role in the expression of pro-inflammatory cytokines, chemokines and anti-microbial peptides. The ability of NF- $\kappa \mathrm{B}$ to support HIF-1alpha activation during hypoxia expands its pro-survival function, since the HIF-1alphadependent hypoxic response is important for providing 
cells and tissues under ischemia with enough energy supplies, allowing them to resist cell death ${ }^{11}$.

A recent study has suggested that HIF-1alpha activation can also occur in response to infections with human pathogens ${ }^{12}$. Up to now, a number of Enterobacteriaceae species ${ }^{13}$, including Escherichia coli ${ }^{14}$, Chlamydia trachomatis $^{15}$, Pseudomonas aeruginosa ${ }^{16,17}$, and group A Streptococcus ${ }^{18}$ have been shown to stabilize HIF-1alpha in both epithelial and immune cells. HIF-1alpha stabilization and its subsequent activation support the discharge of antimicrobial peptides, such as cathelicidins and granule proteases, enhancing the production of nitric oxide and tumor necrosis factor alpha (TNF-alpha) $)^{19,20}$.

Common mechanisms related to infection such as the hypoxic environment created by bacterial oxygen consumption have been proposed to be partly responsible for the HIF-1alpha activation upon infection. Moreover, microbial factors such as chemically synthesized LPS from E. coli $^{21}$ and purified siderophores from Enterobacteriaceae ${ }^{13}$ have also been implicated in the HIF-1alpha stabilization.

However, molecular mechanisms on how bacteria trigger HIF-1alpha remain unclear. Infection of mice with Yersinia enterocolitica led to HIF-1alpha activation in Peyer's patches. Mice with deletion of HIF-1alpha in the intestinal epithelium showed a notably higher susceptibility to Yersinia enterocolitica infections. This phenomenon indicates that bacterial HIF-1alpha activation seems to represent a host defense mechanism. Other studies with Yersinia enterocolitica, Salmonella enterica subsp enterica, or Enterobacter aerogenes with application of their siderophores (aerobactin, salmochelin, yersiniabactin) showed a dose-dependent HIF-1alpha response in human epithelia and endothelia, independent of cellular hypoxia. HIF-1alpha activation occurs most likely because of inhibition of prolyl hydroxylase activity and is abolished upon infection by siderophore-deficient bacteria. Bacterial siderophores have a role in HIF-1alpha activation during infection with human pathogenic bacteria independently of hypoxia. Competition to assimilate iron between bacteria and host cells constitutes a good reason for HIF-1alpha activation in infectious diseases. On the other hand, it is supposed that siderophores of Enterobacteriaceae acting as iron chelators can also inhibit HIF-1alpha degradation ${ }^{13}$.

HIF-1alpha activates autophagy, the natural and destructive mechanism of the cell to eliminate unnecessary or dysfunctional components. This catabolic pathway is involved in cellular homeostasis preservation and xenophagy (a specialized form of autophagy implicated in intracellular bacteria degradation). Many reports have highlighted various roles of autophagy in the regulation of cell death, immunity and antimicrobial response in mammals. Some bacteria are able to impair xenophagy or use it to their survive in cells. This phenomenon seems to happen with adherent-invasive E. coli (AIEC) found inside autophagosomes of immune and epithelial cells. Intracellular survival of these bacteria leads to increased production of inflammatory cytokines. AIEC colonize ileal mucosa of patients with Crohn's disease and play a role in Crohn's pathogenesis by increasing pro-inflammatory and pro-angiogenic responses ${ }^{22}$.

\section{HIF-1ALPHA AND SEPSIS}

HIF-1alpha may mediate the functional reprogramming of monocytes in sepsis. During human sepsis efficient plasticity of monocytes occurs, wherein they changed from a pro-inflammatory to an immunosuppressive phenotype, while enhancing protective actions like antimicrobial activity, phagocytosis and tissue remodeling. This phenomenon signals the potential path of its therapeutic use as a regulator of human sepsis ${ }^{23}$.

HIF-1alpha-deficient macrophages have an impaired metabolic adaptation to hypoxia resulting in decreased motility and migration properties. Moreover, HIF-1alphadeficient macrophages show reduced capacity to kill bacteria. Although the rate of phagocytic uptake of group B Streptococcus was analogous, intracellular killing and lysis of this bacterium were impaired when HIF-1alpha was genetically ablated ${ }^{24}$. Other researches using diverse pathogens have pointed to a possible role of hypoxia and HIF-1alpha in the control of bacterial phagocytosis ${ }^{25}$.

Sepsis is the main cause of death in intensive care units. In this severe clinical condition, an immune response which damages the host often occurs, with LPS shared by gramnegative bacteria acting as a strong activator of immune cells via Toll-like receptor 4 (TLR4). HIF-1alpha is activated by LPS in a TLR4-dependent way and contributes to cytokines activation and lethality in LPS-induced sepsis in vivo.

HIF-1alpha is a decisive determinant of sepsis phenotype through the production of inflammatory cytokines, including IL-1, IL-4, IL-6, IL-12 and TNF-alpha. Excess cytokines may be harmful to the host during early sepsis. HIF-1alpha deletion in macrophages is protective against LPS-induced mortality and HIF is protective against mortality, also preventing clinical progress to hypotension and hypothermia ${ }^{26}$.

Inoculation of live or heat-inactivated grampositive bacteria into macrophages induced HIF-1alpha transcriptional activity in macrophages. According to these results, myeloid deficiency of HIF-1alpha diminished cellular motility caused by gram-positive bacterial endotoxin as well as pro-inflammatory genes expression 
in macrophages. This phenomenon results in decrease of sepsis mortality and clinical symptomatology ${ }^{27}$.

HIF-1alpha activation leads to secretion of VEGF that increase markedly the vascular permeability. Inflammation and infection are associated with increased vascular permeability with tissue edema and vascular leakage ending in septic shock. This dangerous clinical condition might be caused by bacterial-induced HIF-1alpha activation and by VEGF. Therefore, it is not surprising that neutralization of HIF-1alpha-regulated VEGF results in intense decrease of vascular permeability and mortality in sepsis. Several HIF-1alpha-regulated genes have been associated with protection of vascular barrier function during inflammation and hypoxia ${ }^{27}$.

Another interesting knowledge indicates that HIF1alpha activation under hypoxia increases bactericidal activity, and that HIF-1alpha pathways are responsive to bacterial stimulation even under normoxia. Some functions of myeloid cells as endothelial transmigration and respiratory burst activation appear to be independent of HIF-1alpha control. On the other hand, this mediator is involved in the regulation of specific immune functions, including granule proteases, nitric oxide, and cathelicidin antimicrobial peptides. Marked reduction of granule protease and cathelicidin expression in HIF-1alphadeficient neutrophils correlates with reduced bactericidal activity in vitro and failure to control infection in vivo. This knowledge provides support to new studies uncovering a key role for these neutrophil effectors in mammalian innate immunity ${ }^{28}$.

\section{HIF-1ALPHA AND BACTERIA}

Infections with the angiogenic bacterium Bartonella henselae (bacillary angiomatosis disease) result in HIF-1alpha activation both in vitro and in vivo, probably via hypoxia-associated metabolic alterations. Activation of HIF-1alpha by human pathogenic Enterobacteriaceae seems to follow a more general pattern of bacterial infections including the induction of iron deficiency in host cells by bacterial siderophores due to a hypoxia-independent HIF-1alpha activation ${ }^{29}$.

Shigella flexneri is a gram-negative bacterium responsible for intense intestinal end systemic infection in humans. These bacteria can reach the liver and other organs due to deterioration of the colonic epithelium. In a study of our laboratory, Shigella flexneri invaded less cultured hepatocytes previously submitted to hypoxia $\left(6.5 \% \mathrm{O}_{2}\right)$ for $24 \mathrm{~h}$ than those cultured under normoxia conditions. In this study, HIF-1alpha expression has also enhanced in hepatocytes as well as TNF-alpha secretion and apoptosis rate. This bacterium was able to invade rat hepatocytes and hypoxia has significantly decreased cell invasiveness by this bacterium ${ }^{30}$.

Several host factors contribute to higher expression of HIF-1alpha and related immune/metabolic responses during Mycobacterium tuberculosis (Mtb) infection both in vitro and in vivo. One factor is nitric oxide (NO) which arises by action of an inducible NO synthase (NOS2/iNOS) in infected murine macrophages. NOS2/iNOS induction may result in redistribution of intracellular oxygen and inhibition of PHDs (negative controllers of HIF-1alpha) forming a positive feedback loop that leads to a sustained high level of HIF-1alpha and increases macrophage activation. During Mtb infection, expression of NF- $\mathrm{KB}$ family members are upregulated in macrophages (mouse and rabbit lungs), as well as in the granulomas of patients with pulmonary tuberculosis. Regarding NF- $\kappa \mathrm{B}$ activation, IkappaB kinases (IKK) are necessary for the phosphorylation-induced degradation of NF- $\kappa B$ inhibitors in response to infection and inflammation. IKK- $\beta$ is also important for HIF-1alpha accumulation in macrophages during bacterial infection. $\mathrm{NF}-\mathrm{KB}$ proteins then dimerize and translocate into the nucleus to activate the transcription of HIF-1alpha and other target genes ${ }^{31}$.

Several studies have reported the abnormal presence of intramucosal Escherichia coli or mucosa-associated Escherichia coli with invasive properties in patients with Crohn's disease (CD) or colorectal cancer. Adherentinvasive Escherichia coli (AIEC) colonize ileal lesions by $\mathrm{CD}$ and induce local inflammation. HIF-1alpha is highly expressed in inflamed ileal epithelium of CD patients inducing expression of pro-inflammatory cytokines (IL-1 $\beta$, IL-6 and IL-17), as well as decreased expression of antiinflammatory cytokines such as IL-10. CEACAM6, a protein that acts as a receptor of AIEC is expressed in this particular condition. Using CEABAC 10 transgenic mice that express CEACAM6, it was demonstrated that AIEC bacteria induce production of HIF-1alpha protein and activation of VEGF/VEGFR signaling. Downstream analyses on human intestinal epithelial cells silenced for HIF-1alpha, highlight the critical role of this protein in production of pro-angiogenic factors. This study highlights the crucial role of AIEC bacteria as a promoter of inflammatory disorders of the gastrointestinal tract and offers clear evidence that HIF-1alpha protein plays a main role in mediating this effect ${ }^{32}$.

HIF-1alpha gene knockdown increased AIEC survival in intestinal epithelial cells in another study. AIEC survival rate increment was associated with an intense impairment of the autophagic flux at the autolysosomal maturation stage. A new function for HIF-1alpha in xenophagy linked to AIEC 
was shown and this phenomenon suggests that co-activation of autophagy and HIF1-alpha expression may be a possible new therapy to combat AIEC infection in CD patients ${ }^{22}$.

Pseudomonas aeruginosa cell-free supernatant dramatically suppressed HIF-1alpha protein levels. Further characterization revealed that HIF-1alpha downregulation was dependent on a subclass of key secreted factors involved in Pseudomonas aeruginosa pathogenesis. These factors are the 2-alkyl-4-quinolone (AQ) quorum sensing (QS) signaling molecules and in particular the Pseudomonas quinolone signal $(\mathrm{PQS})^{20}$. The finding that Pseudomonas aeruginosa AQ signaling molecules suppressed HIF-1alpha protein levels was unexpected, because bacterial components had been shown to lead to HIF-1alpha protein accumulation. This research was the first report on a bacterial factor capable of suppressing HIF-1alpha stabilization ${ }^{20}$.

HIF-1alpha may play a role in the coordinated response of airway cells to Staphylococcus aureus (S. aureus) infection. S. aureus also lead cells to necrosis rather than apoptosis.One main $S$. aureus infection characteristic concerns its ability to favor subsequent infections by gramnegative bacteria such as $P$. aeruginosa in cystic fibrosis patients ${ }^{33}$.

The relationship between HIF-1alpha and Staphylococcus aureus infections was also shown in another way. Transcriptional profiling of HIF-1alpha-deficient HepG2 and control cells was made by using Staphylococcus aureus infections. The expression of 190 genes was influenced, being 24 of them regulated via HIF-1alpha, four hours after infection. LOX (encoding lysyl oxidase) was one of the upregulated genes with a probable impact on the progress of $S$. aureus infection. LOX is an amine oxidase essential for biosynthetic cross-linking of extracellular matrix components. LOX was upregulated in vitro in different cell cultures infected with S. aureus and in kidney abscesses of mice infected with $S$. aureus, as well as in skin samples from patients with $S$. aureus infections. Inhibition of LOX by aminopropionitrile (APN) did not affect the bacterial load in kidneys or blood, but significantly influenced abscess morphology. These data provide evidence for a central role of HIF-1alpha-regulated LOX in abscess development ${ }^{34}$.

HIF-1alpha activation in infectious diseases seems to be induced by several overlapping mechanisms, including greater oxygen consumption at the site of infection, iron deficiency and some bacterial components (e.g., outer membrane proteins such as Bartonella adhesin A or LPS from E. coli). HIF-1alpha has a protective role in local infections being essential for the bactericidal capacity of phagocytes besides controlling the systemic spread of bacteria $^{17,24}$. In contrast, HIF-1alpha activation appears to be unfavorable in systemic infections leading to higher mortality, as occurs in sepsis induced by LPS and S. aureus peritonitis models ${ }^{12,26}$.

HIF-1alpha agonist mimosine can increase the capacity of human phagocytes and whole blood to kill Staphylococcus aureus in a dose-dependent mode. This phenomenon reduces the lesion dimension in a murine model of $S$. aureus skin infection and represents a new approach for the treatment of this bacterial infection ${ }^{35}$.

Helicobacter pylori ( $H$. pylori) induces reactive oxygen species (ROS), which are implicated in peptic ulcer disease and gastric cancer. Gastric epithelial ROS, either endogenous or induced by $\mathrm{H}$. pylori, improve normoxic HIF-1alpha expression in gastric mucosa. ROS also stimulate a ubiquitous multifunctional protein, apurinic/apyrimidinic endonuclease 1 (APE1). There is also an important role of ROS-HIF-1alpha axis in VEGF production by $H$. pylori infected gastric epithelial cells. The bacterial T4SS has a minor role in $H$. pylori-induced VEGF production by gastric epithelial cells ${ }^{36}$.

ROS induced by H. pylori stabilize HIF-1alpha in the human gastric epithelium under normoxia. HIF-1alpha plays a decisive role in carcinogenesis and has been related to malignant progression of gastric cancer. Several genes encode functional hypoxia-response elements (HREs) in their promoters including Mcl1 (Bcl2 family member). Cellular ratios of Mcl1, antiapoptotic oncogenic protein and tumor suppressor pro-apoptotic protein regulate cell destiny by regulating normal cellular growth, cell death and oncogenic processes ${ }^{37}$.

\section{HIF-1ALPHA AND VIRUS}

Hepatitis C virus (HCV) protein triggers HIF-1alpha by normoxic stabilization of its subunit. The expression of HIF-controlled genes is significantly upregulated including those coding for glycolytic enzymes. Analogous expression of HIF-controlled genes was observed in cell lines expressing subgenomic HCV particles encoding either structural or nonstructural viral proteins. Stabilization and transcriptional HIF-1alpha activation was established in Huh-7.5 cells harboring cell culture-derived infectious $\mathrm{HCV}$ and in liver biopsy samples from patients with chronic hepatitis C. The HCV-related HIF-1alpha stabilization was unresponsive to antioxidant treatment ${ }^{38}$.

In a recent report ${ }^{39}$, it was shown that $\mathrm{HCV}$ infection causes oxidant-mediated HIF-1alpha stabilization, leading to expression of vascular endothelial growth factor (VEGF). The relationship among HCV core protein, induction of HIF-1alpha and VEGF expression was also shown in another research, when the HCV core gene and 
HIF-1alpha siRNA were transfected into Huh7.5.1 cells. These results demonstrated that induction of HCV core gene expression in Huh7.5.1 cells leads to over expression and stabilization of HIF-1alpha. In addition, the HIF-1alpha activation leads to stimulation of $\mathrm{VEGF}^{40}$. In this last study, the authors have also shown that long-term HCV protein expression produced depression of mitochondrial oxidative phosphorylation. Cell survival was preserved by higher use of glucose non-oxidative pathway. This adaptive response to $\mathrm{HCV}$-induced mitochondrial injury proved to be mediated by stabilization of HIF-1alpha and upregulation of glycolytic enzymes. Comparable results were found in two different cell culture systems and in liver biopsy specimens from HCV-infected patients ${ }^{40}$.

HIF-1alpha was induced after infection of human fibroblasts with human cytomegalovirus (HCMV). HCMV irradiated with ultraviolet light (HCMV-U) has also provoked this effect, showing that response was caused by the interaction of infective virion with the cell, without viral gene expression. Increase of HIF-1alpha protein was not detected until 9 hours post infection. Infection with HCMV-U resulted in increased HIF-1alpha specific RNA, and this fact indicates stimulation of transcription ${ }^{41}$.

Current studies have shown that HIF-1alpha also plays an important task in Kaposi's sarcoma-associated herpesvirus (KSHV) reactivation from latency. Specific interaction between KSHV viral IFN regulatory factor 3 (vIRF3) and the HIF-1alpha subunit led to HIF-1alpha stabilization and transcriptional activation, which induced VEGF expression and finally facilitated endothelial tube formation. The central domain of vIRF3 was sufficient for binding to HIF-1alpha and for blocking its degradation under normoxic conditions. This fact shows that KSHV has developed a unique mechanism to enhance HIF-1alpha protein stability by incorporating a viral homologue of cellular IRF gene into its genome, which may contribute to viral pathogenesis ${ }^{42}$.

Human papillomaviruses (HPVs) are non-enveloped DNA viruses that persistently infect keratinocytes of stratified squamous epithelia. HPVs are related to a diversity of malignancies, more than $99 \%$ of cervical cancers ${ }^{43}$. In a study, the levels of HIF-1alpha protein was increased in hypoxia when HPV oncogenes was present, and this was true for all types of risk viruses. Moreover, this increased HIF-1alpha induction resulted in increments of some effectors downstream of the hypoxic response, suggesting that HPV manipulates some aspects of the cellular hypoxic response $^{43}$. HPV-16 E6 and E7 oncoproteins contribute to the progress of non-small cell lung cancer (NSCLC) perhaps by promoting tumor angiogenesis via HIF-1alpha/VEGF pathways, which may serve as potential molecular targets for the treatment of HPV-related NSCLC ${ }^{44}$.

\section{HIF-1ALPHA AND PROTOZOAN PARASITES}

Toxoplasma gondii is an obligate intracellular protozoan pathogen. Some studies have presented that genes mediating cellular responses to hypoxia were upregulated in Toxoplasmainfected cells but not in cells infected with Trypanosoma cruzi, another intracellular pathogen. Expression of these genes is controlled by HIF-1alpha. Toxoplasma infection rapidly increased the quantity of HIF1 alpha subunit and activated its reporter gene expression. Toxoplasma growth and survival was strictly reduced in HIF-1alpha knockout cells at 3\% oxygen. HIF-1alpha was not required for parasite invasion, but it was necessary for parasite cell division and organelle preservation at $3 \%$ oxygen ${ }^{45}$. Several authors have found that Toxoplasma infection increased the quantity of transcripts encoding glycolytic enzymes, glucose transporters, transferrin receptor and vascular endothelial growth factor (VEGF) ${ }^{46,47}$.

Leishmania donovani (LD), a protozoan parasite and the causative agent of fatal visceral leishmaniosis lives in macrophages within mammalian hosts. In a study, J774 macrophages were infected with LD and a four-fold increase in HIF-1alpha expression was detected. A strong rise in HIF-1alpha expression and its nuclear location was also shown in peritoneal macrophages and in spleen-derived macrophages of LD infected BALB/c mice. A two-fold increase in HIF-1alpha mRNA was found in LD-infected macrophages suggesting participation of a transcriptional mechanism that was confirmed by promoter activity. LD also induces HIF-1alpha expression by reducing host cellular iron pool to affect prolyl hydroxylase activity, with stabilization of HIF-1alpha. These results suggest that LD activates HIF-1alpha by dual mechanism for its survival advantage within macrophages ${ }^{48}$.

In another study, it has been shown that hypoxia induced macrophages to control Leishmania amazonensis (LA), an intracellular parasite that causes cutaneous metastatic lesions. Nitric oxide, TNF- alpha, IL-10 or IL-12 are not responsible for the decline in parasitism under hypoxia. Reactive oxygen species (ROS) are likely to be involved, because treatment with antioxidants $\mathrm{N}$-acetylcysteine (NAC) prevents the leishmanicidal effect of macrophages under hypoxia. LA infection induces macrophages to express HIF-1alpha. Data indicate that hypoxia affects microbial activities and protein expression of macrophages leading to a phenotype different from that found in the counterpart under normoxia conditions, which plays a role in modulating LA infection ${ }^{49}$.

\section{HIF-1ALPHA AND FUNGI}

Aspergillus fumigatus is an opportunistic fungal pathogen that causes invasive pulmonary aspergillosis 
(IPA) in immunocompromised individuals, particularly in hematopoietic stem cell transplant recipients and patients with acute leukemia ${ }^{50}$. As a new treatment approach for infectious diseases, HIF-1alpha is presently being considered as a possible pharmacological target for host immune defense ${ }^{51}$. HIF-1alpha plays a main role in immune functions of phagocytes including dendritic cells (DCs). DCs are essential cells in anti-A. fumigatus immune responses. DCs express the pattern recognition receptor (PRR) dectin-1 that is involved in recognition of A. fumigatus $^{52}$. A complex regulatory network organizes inflammatory processes following dectin-1 binding, including activation of the NF-kB protein complex, a key regulator of cytokine production and cell survival. Notably, the cross-talk between NF-kB and HIF-1alpha binds cellular responses against infection and hypoxia ${ }^{11}$. Besides, the transcriptional activity of HIF-1alpha in DCs varies depending on whether it is activated via TLRs or hypoxia ${ }^{53}$. This fact suggests that the influence of HIF-1alpha on the immune response depends on oxygen levels and the pathogen activity in the infection microenvironment ${ }^{54}$.

Infection with Aspergillus fumigatus represents a major cause of morbidity in lung transplantation receivers with mortality rates up to $82 \%$. Infections after lung transplantation may also cause obliterative bronchiolitis, invasive pulmonary aspergillosis and airway anastomotic infections ${ }^{55,56}$.

HIF-1 alpha appears to exert several protective functions on mucosal surfaces like defensins production ${ }^{57}$. The aging process prevents normal angiogenic cell mobilization and can be restored through the improvement of HIF-1 activity $^{58}$. In addition, increased HIF-1alpha activity may be effective primarily to prevent chronic rejection in elderly transplant recipients ${ }^{59}$.

HIF-1alpha is implicated in priming innate immune system by $C$. albicans infection, as already mentioned above, through cathelicidin-related antimicrobial peptides (CRAMP). These elements are a family of polypeptides that provide a critical role in innate immune defense against bacterial infection. Human cathelicidin LL-37 has been shown to have anti-Candida activity ${ }^{60}$ and inhibits Candida adhesion to epithelial surfaces ${ }^{61,62}$. In the gastrointestinal tract, commensal bacteria induced HIF-1alpha which was important in mediating resistance to $C$. albicans colonization by promoting CRAMP (Fan et al. 2015). CRAMP is a homolog of the human cathelicidin LL-37 which caused killing of C. albicans in vitro $6^{60,63}$.

Although immunocompetent hosts usually resolve Histoplasma capsulatum (HC) infections with minimal symptoms, severe infections can occur in immunocompromised individuals. The incidence of hypoxia and the importance of HIF-1alpha in dictating antimicrobial activity, metabolism, and cytokine generation requires considering the role of this transcription factor in the response to $\mathrm{HC}$ infection. In a study, the authors infected myeloid-specific HIF-1alpha knockout mice by the pulmonary route with $\mathrm{HC}$. The absence of myeloid HIF-1alpha decreased survival and increased fungal load as early as day 3 post infection. The collapse of immunity was not related to reduction of lung pro-inflammatory protective cytokines, but rather to an increase of IL-10. HIF-1alpha was important for controlling the progression of infection with the fungal pathogen $\mathrm{HC}$ by limiting IL- $10^{64}$.

HIF-1alpha has also a vital role in the macrophage response to HC. It was transcriptionally upregulated and stabilized in $\mathrm{HC}$ infected macrophages under normoxia. HIF-1alpha increased the innate response to this fungus by modulating the production of IL-10 in macrophages ${ }^{63}$. An interesting finding showed that the $\mathrm{HC}$-induced granuloma was hypoxic in liver of mice during disseminated histoplasmosis, and HIF-1alpha was transcriptionally upregulated in liver and lung tissues homogenates during disseminated and pulmonary histoplasmosis, respectively. Macrophage was the main cell population in liver granuloma and $95 \%$ of these were hypoxic and therefore might produce HIF-1alpha protein in granulomatous tissue. Phagocytosis of $\mathrm{HC}$ by macrophage is partially mediated by complement receptor 3 (CR3) as shown for other pathogenic fungi. CR3 synergizes with Dectin-1, the major beta-glucan receptor, and orchestrates a pro-inflammatory cytokine response via spleen tyrosine kinase (Syk) that might contribute to high HIF-1alpha protein levels in infected macrophages ${ }^{64}$. Subsequent studies showed that the presence of HIF-1alpha in macrophages is critically essential for a functional innate immune response to HC. HIF-1alpha-deficient mice showed high mortality, despite the production of pro-inflammatory cytokines such as IL-1beta and TNF-alpha, known to be significant for effective immune responses ${ }^{64}$.

There is only one study showing the potential role of HIF-1alpha in Coccidioides immitis (CI) infection. Differences between immune functions of CI-susceptible and -protected mice strains were investigated. Transcription of HIF-1alpha and pro-inflammatory cytokines such as IFN-gamma and TNF-alpha were increased in resistant mice strains, which might favor fungal immunity, and IFN-gamma was shown to be protective against $\mathrm{CI}^{65}$.

\section{PERSPECTIVES}

Current findings increase the importance of HIF-1alpha in regulating immune cell activity. HIF-1alpha activation under hypoxia microenvironment enhances bactericidal 
activity. HIF-1alpha also regulates myeloid cell aggregation, invasion, motility and internalization of bacteria through effects linked in part to intracellular ATP levels. The present knowledge indicates that the initial induction of HIF-1alpha is enough to activate a signaling cascade leading to enhanced phagocytosis in vitro and in vivo. These data raise the possibility that HIF-1alpha itself may have a key role in host defense during systemic inflammation, mainly when oxygen delivery is impaired.

The current comprehension suggest that a rational design of pharmaceutical HIF-1alpha agonists (or vHL antagonists) to enhance myeloid cell microbicidal activity may represent a new approach for adjunctive therapy of complex infections due to antibiotic-resistant pathogens or compromised host immunity. HIF-1alpha has become more and more investigated as a target against bacterial infections, an approach that might be effective against multidrugresistant infections. Some authors have encouraged discussion of HIF-1alpha modulation as a pharmacologic goal for the treatment of chronic inflammatory disorders or to increase innate immune function ${ }^{26}$. Inhibition of HIF-1alpha activity may also characterize a new therapeutic target for LPS-induced sepsis ${ }^{26}$.

Tissue hypoxia and HIF-1alpha signaling have been implicated in several diseases, turning this pathway into an attractive target for therapeutic intervention. Future therapeutic strategies aimed at targeting HIF-1alpha to treat diseases such as infections, cancer and inflammation will depend on better knowledge of the primary biology of these conditions, through the use of physiologically pertinent disease models. The newer models such as the zebrafish, in concert with more traditional cell lines and murine models, could help to understand the extent of the effects that HIF modulation will produce on cellular physiology. Exploiting these relationships, pharmacological stabilization of HIF1alpha may increase phagocyte-mediated clearance of infectious agents, providing the first evidence for a novel approach to to treat bacterial infections by pharmacologically augmenting host phagocytic cells function ${ }^{66}$.

\section{CONCLUSIONS}

Several evidences show that HIF-1alpha has a significant role in determining the outcome of diseases such as cancer, inflammatory and infectious diseases. HIF-1alpha plays a regulatory role in reply to a diversity of molecular signals of infection and inflammation. HIF-1alpha is also induced by pro-inflammatory cytokines, growth factors and a wide range of infections, and its production is a general element of the host response to infection. There are evidences that HIF-1alpha expression influences the outcome of infections caused by numerous different agents: bacteria, viruses, fungi and protozoa. HIF-1alpha has therefore become increasingly investigated as a target against infections, a strategy that may be efficient in multidrug-resistant infections.

\section{REFERENCES}

1. Sendoel A, Hengartner MO. Apoptotic cell death under hypoxia. Physiology (Bethesda). 2014;29:168-76.

2. Wang GL, Semenza GL. Purification and characterization of hypoxia inducible factor 1. J Biol Chem. 1995;270:12307.

3. Darby IA, Hewitson TD. Hypoxia in tissue repair and fibrosis. Cell Tissue Res. 2016;365:553-62.

4. Kaluz S, Kaluzová M, Stanbridge EJ. Proteasomal inhibition attenuates transcriptional activity of hypoxia-inducible factor 1 (HIF-1alpha) via specific effect on the HIF-1alpha C-terminal activation domain. Mol Cell Biol. 2006;26:5895-907.

5. Freedman SJ, Sun ZY, Poy F, Kung AL, Livingston DM, Wagner $\mathrm{G}$, et al. Structural basis for recruitment of CBP/p300 by hypoxia-inducible factor- $1 \alpha$. Proc Natl Acad Sci U S A. 2002;99:5367-72.

6. Kaluz S, Kaluzová M, Stanbridge EJ. Regulation of gene expression by hypoxia: integration of the HIF-transduced hypoxic signal at the hypoxia-responsive element. Clin Chim Acta. 2008;395:6-13.

7. Halterman MW, Miller CC, Federoff HJ. Hypoxia-inducible factor- $1 \alpha$ mediates hypoxia-induced delayed neuronal death that involves p53. J Neurosci. 1999;19:6818-24.

8. Kaluz S, Kaluzová M, Stanbridge EJ. Does inhibition of degradation of hypoxia-inducible factor (HIF) always lead to activation of HIF? Lessons learnt from the effect of proteasomal inhibition on HIF activity. J Cell Biochem. 2008;104:536-44.

9. Chachami G, Paraskeva E, Georgatsou E, Bonanou S, Simos G. Bacterially produced human HIF-1alpha is competent for heterodimerization and specific DNA-binding. Biochem Biophys Res Commun. 2005;331:464-70.

10. Fedulova N, Hanrieder J, Bergquist J, Emrén LO. Expression and purification of catalytically active human PHD3 in Escherichia coli. Protein Expr Purif. 2007;54:1-10.

11. Rius J, Guma M, Schachtrup C, Akassoglou K, Zinkernagel AS, Nizet $\mathrm{V}$, et al. NF- $\kappa \mathrm{B}$ links innate immunity to the hypoxic response through transcriptional regulation of HIF $\alpha$. Nature. 2008;453:807-11.

12. Werth N, Beerlage C, Rosenberger C, Yazdi AS, Edelmann M, Amr A, et al. Activation of hypoxia inducible factor 1 is a general phenomenon in infections with human pathogens. PLoS One. 2010;5:e11576.

13. Hartmann H, Eltzschig HK, Wurz H, Hantke K, Rakin A, Yazdi AS, et al. Hypoxia-independent activation of HIF-1alpha by enterobacteriaceae and their siderophores. Gastroenterology. 2008;134:756-67. 
14. Cane G, Ginouvès A, Marchetti S, Buscà R, Pouysségur J, Berra E, et al. HIF-1alpha mediates the induction of IL-8 and VEGF expression on infection with Afa/Dr diffusely adhering E. coli and promotes EMT-like behaviour. Cell Microbiol. 2010;12:640-53.

15. Sharma M, Machuy N, Böhme L, Karunakaran K, Mäurer AP, Meyer TF, et al. HIF-1alpha is involved in mediating apoptosis resistance to Chlamydia trachomatis-infected cells. Cell Microbiol. 2011;13:1573-85.

16. Legendre C, Mooij MJ, Adams C, O’Gara F. Impaired expression of hypoxia-inducible factor-1alpha in cystic fibrosis airway epithelial cells - a role for HIF-1alpha in the pathophysiology of CF? J Cyst Fibros. 2011;10:286-90.

17. Peyssonnaux C, Datta V, Cramer T, Doedens A, Theodorakis EA, Gallo RL, et al. HIF-1alpha expression regulates the bactericidal capacity of phagocytes. J Clin Invest. 2005;115:1806-15.

18. Peyssonnaux C, Boutin AT, Zinkernagel AS, Datta V, Nizet V, Johnson RS. Critical role of HIF-1alpha in keratinocyte defense against bacterial infection. J Invest Dermatol. 2008;128:1964-8.

19. Nizet V, Johnson RS. Interdependence of hypoxic and innate immune responses. Nat Rev Immunol. 2009;9:609-17.

20. Legendre C, Reen FJ, Mooij MJ, McGlacken JP, Adams C, O'Garaa F. Pseudomonas aeruginosa alkyl quinolones repress hypoxia-inducible factor 1 (HIF-1alpha) signaling through HIF-1alpha degradation. Infect Immun. 2012;80:3985-92.

21. Frede S, Stockmann C, Freitag P, Fandrey J. Bacterial lipopolysaccharide induces HIF-1alpha activation in human monocytes via p44/42 MAPK and NF-kappaB. Biochem J. 2006;396:517-27.

22. Mimouna S, Bazin M, Mograbi B, Darfeuille-Michaud A, Brest $\mathrm{P}$, Hofman $\mathrm{P}$, et al. HIF1A regulates xenophagic degradation of adherent and invasive Escherichia coli (AIEC). Autophagy. 2014;10:2333-45.

23. Shalova IN, Lim JY, Chittezhath M, Zinkernagel AS, Beasley F, Hernández-Jiménez, et al. Human monocytes undergo functional re-programming during sepsis mediated by hypoxiainducible factor-1alpha. Immunity. 2015;42:484-98.

24. Cramer T, Yamanishi Y, Clausen BE, Förster I, Pawlinski R, Mackman N, et al. HIF-1alpha is essential for myeloid cell mediated inflammation. Cell. 2003;112:645-57.

25. Palazon A, Goldrath AW, Nizet V, Johnson RS. HIF transcription factors, inflammation, and immunity. Immunity. 2014;41:518-28.

26. Peyssonnaux C, Cejudo-Martin P, Doedens A, Zinkernagel AS, Johnson RS, Nizet V. Cutting edge: essential role of hypoxia inducible factor-1 alpha in development of lipopolysaccharideinduced sepsis. J Immunol. 2007;178:7516-9.

27. Mahabeleshwar GH, Qureshi MA, Takami Y, Sharma N, Lingrel JB, Jain MK. A myeloid hypoxia-inducible factor 1-Krüppellike factor 2 pathway regulates gram-positive endotoxinmediated sepsis. J Biol Chem. 2012;287:1448-57.
28. Reeves EP, Lu H, Jacobs HL, Messina CG, Bolsover S, Gabella $\mathrm{G}$, et al. Killing activity of neutrophils is mediated through activation of proteases by K+ flux. Nature. 2002;416:291-7.

29. Gardlik R, Hodosy J, Palffy R, Behuliak M, Janega P, Celeca P. Effects of orally administered bacteria carrying HIF-1alpha gene in an experimental model of intestinal ischemia. Arch Med Res. 2010;41:332-7.

30. Lima CB, Santos SA, Andrade Júnior DR. Quantification of the expression of HIF-alpha by Real-Time PCR in rat hepatocytes cultures invaded by Shigella flexneri under normoxic and hypoxic conditions. Adv Microbiol. 2015;5:507-16.

31. Shi L, Eugenin EA, Subbian S. Immunometabolism in tuberculosis. Front Immunol. 2016;7:150.

32. Mimouna S, Gonçalves D, Barnich N, Darfeuille-Michaud A, Hofman P, Vouret-Craviari V. Crohn disease-associated Escherichia coli promote gastrointestinal inflammatory disorders by activation of HIF-dependent responses. Gut Microbes. 2011;2:335-46.

33. Moreihon C, Gras D, Hologne C, Bajolet O, Cottrez F, Magnone $\mathrm{V}$, et al. Live Staphylococcus aureus and bacterial soluble factors induce different transcriptional responses in human airway cells. Physiol Genomics. 2005;20:244-55.

34. Beerlage C, Greb J, Kretschmer D, Assaggaf M, Trackman PC, Hansmann ML, et al. Hypoxia-inducible factor 1-regulated lysyl oxidase is involved in Staphylococcus aureus abscess formation. Infect Immun. 2013;81:2562-73.

35. Zinkernagel AS, Peyssonnaux C, Johnson RS, Nizet V. Pharmacologic augmentation of hypoxia-inducible factor-1 with mimosine boosts the bactericidal capacity of phagocytes. J Infect Dis. 2008;197:214-7.

36. Kang MJ, Song EJ, Kim BY, Kim DJ, Park JH. Helicobacter pylori induces vascular endothelial growth factor production in gastric epithelial cells through hypoxia-inducible factor1alpha-dependent. Helicobacter. 2014;19:476-83.

37. Bhattacharyya A, Chattopadhyay R, Hall EH, Mebrahtu ST, Ernst PB, Crowe SE. Mechanism of hypoxia-inducible factor 1-mediated Mcl1 regulation in Helicobacter pylori-infected human gastric epithelium. Am J Physiol Gastrointest Liver Physiol. 2010;299:G1177-86.

38. Ripoli M, D’Aprile A, Quarato G, Sarasin-Filipowicz M, Gouttenoire J, Scrima R, et al. Hepatitis C virus-linked mitochondrial dysfunction promotes hypoxia-inducible factor 1-mediated glycolytic adaptation. J Virol. 2010;84:647-60.

39. Nasimuzzaman M, Waris G, Mikolon D, Stupack DG, Siddiqui A. Hepatitis $C$ virus stabilizes hypoxia-inducible factor 1alpha and stimulates the synthesis of vascular endothelial growth factor. J Virol. 2007;81:10249-57.

40. Zhu C, Liu X, Wang S, Yan X, Tang Z, Wu K, et al. Hepatitis $\mathrm{C}$ virus core protein induces hypoxia-inducible factor $1 \alpha$-mediated vascular endothelial growth factor expression in Huh7.5.1 cells. Mol Med Rep. 2014;9:2010-4. 
41. McFarlane S, Nicholl MJ, Sutherland JS, Preston CM. Interaction of the human cytomegalovirus particle with the host cell induces hypoxia-inducible factor 1 alpha. Virology. 2011;414:83-90

42. Shin YC, Joo CH, Gack MU, Lee HR, Jung JU. Kaposi's sarcomaassociated herpesvirus viral IFN regulatory factor 3 stabilizes hypoxia-inducible factor-1A to induce vascular endothelial growth factor expression. Cancer Res. 2008;68:1751-9.

43. Nakamura M, Bodily JM, Beglin M, Kyo S, Inoue M, Laimins LA. Hypoxia-specific stabilization of HIF-1alpha by human papillomaviruses. Virology. 2009;387:442-8.

44. Li G, He L, Zhang E, Shi J, Zhang Q, Le AD, et al. Overexpression of human papillomavirus (HPV) type 16 oncoproteins promotes angiogenesis via enhancing HIF-1a and VEGF expression in non-small cell lung cancer cells. Cancer Lett. 2011;311:160-70.

45. Spear W, Chan D, Coppens I, Johnson RS, Giaccia A, Blader IJ. The host cell transcription factor hypoxia-inducible factor 1 is required for Toxoplasma gondii growth and survival at physiological oxygen levels. Cell Microbiol. 2006;8:339-52.

46. Blader IJ, Manger ID, Boothroyd JC. Microarray analysis reveals previously unknown changes in Toxoplasma gondii-infected human cells. J Biol Chem. 2001;276:24223-31.

47. Gail M, Gross U, Bohne W. Transcriptional profile of Toxoplasma gondii-infected human fibroblasts as revealed by gene-array hybridization. Mol Genet Genomics. 2001;265:905-12.

48. Singh AK, Mukhopadhyay C, Biswas S, Singh VK, Mukhopadhyay CK. Intracellular pathogen Leishmania donovani activates hypoxia inducible factor-1 by dual mechanism for survival advantage within macrophage. PLoS One. 2012;7:e38489.

49. Degrossoli A, Arrais-Silva WW, Colhone MC, Gadelha FR, Joazeiro PP, Giorgio S. The influence of low oxygen on macrophage response to Leishmania infection. Scand J Immunol. 2011;74:165-75.

50. Park SJ, Mehrad B. Innate immunity to Aspergillus species. Clin Microbiol Rev. 2009;22:535-51.

51. Bhandari T, Nizet V. Hypoxia-inducible factor (HIF) as a pharmacological target for prevention and treatment of infectious diseases. Infect Dis Ther. 2014;3:159-74.

52. Lother J, Breitschopf T, Krappmann S, Morton CO, Bouzani M, Kurzai O, et al. Human dendritic cell subsets display distinct interactions with the pathogenic mould Aspergillus fumigatus. Int J Med Microbiol. 2014;304:1160-8.

53. Jantsch J, Wiese M, Schödel J, Castiglione K, Gläsner J, Kolbe $\mathrm{S}$, et al. Toll-like receptor activation and hypoxia use distinct signaling pathways to stabilize hypoxia-inducible factor 1alpha (HIF1A) and result in differential HIF1A-dependent gene expression. J Leukoc Biol. 2011;90:551-62.

54. Fliesser M, Morton CO, Bonin M, Ebel F, Hünniger K, Kurzai $\mathrm{O}$, et al. Hypoxia-inducible factor 1 modulates metabolic activity and cytokine release in anti-Aspergillus fumigatus immune responses initiated by human dendritic cells. Int $\mathbf{J}$ Med Microbiol. 2015;305:865-73.

55. Weigt SS, Copeland CA, Derhovanessian A, Shino MY, Davis WA, Snyder LD, et al. Colonization with small conidia Aspergillus species is associated with bronchiolitis obliterans syndrome: a two-center validation study. Am J Transplant. 2013;13:919-27.

56. Solé A, Morant P, Salavert M, Pemán J, Morales P. Aspergillus infections in lung transplant recipients: risk factors and outcome. Clin Microbiol Infect. 2005;11:359-65.

57. Kelly CJ, Glover LE, Campbell EL, Kominsky DJ, Ehrentraut SF, Bowers BE, et al. Fundamental role for HIF-1alpha in constitutive expression of human beta defensin-1. Mucosal Immunol. 2013;6:1110-8.

58. Bosch-Marce M, Okuyama H, Wesley JB, Sarkar K, Kimura H, Liu YV, et al. Effects of aging and hypoxia-inducible factor-1 activity on angiogenic cell mobilization and recovery of perfusion after limb ischemia. Circ Res. 2007;101:1310-8.

59. Jiang X, Hsu JL, Tian W, Yuan K, Olcholski M, Perez VJ, et al. Tie2-dependent VHL knockdown promotes airway microvascular regeneration and attenuates invasive growth of Aspergillus fumigatus. J Mol Med (Berl). 2013;91:1081-93.

60. López-García B, Lee PH, Yamasaki K, Gallo RL. Anti-fungal activity of cathelicidins and their potential role in Candida albicans skin infection. J Invest Dermatol. 2005;125:108-15.

61. Elks PM, Renshaw SA, Meijer AH, Walmsley SR, van Eeden FJ. Exploring the HIFs, buts and maybes of hypoxia signaling in disease: lessons from zebrafish models. Dis Model Mech. 2015;8:1349-60.

62. Fan D, Coughlin LA, Neubauer MM, Kim J, Kim MS, Zhan X, et al. Activation of HIF-1 $\alpha$ and LL-37 by commensal bacteria inhibits Candida albicans colonization. Nat Med. 2015;21:80814.

63. Friedrich D, Fecher RA, Rupp J, Deepe GS Jr. Impact of HIF1a and hypoxia on fungal growth characteristics and fungal immunity. Microbes Infect 2017;19:204-9.

64. Fecher RA, Horwath MC, Friedrich D, Rupp J, Deepe GS Jr. Inverse correlation between IL-10 and HIF- $1 \alpha$ in macrophages infected with Histoplasma capsulatum. J Immunol. 2016;197:565-79.

65. Woelk CH, Zhang JX, Walls L, Viriyakosol S, Singhania A, Kirkland TN, et al. Factors regulated by interferon gamma and hypoxia inducible factor $1 \mathrm{~A}$ contribute to responses that protect mice from Coccidioides immitis infection. BMC Microbiol. 2012;12:218.

66. Okumura CY, Hollands A, Tran DN, Olson J, Dahesh S, von Köckritz-Blickwede M, et al. A new pharmacological agent (AKB-4924) stabilizes hypoxia inducible factor-1 (HIF-1alpha) and increases skin innate defenses against bacterial infection. J Mol Med (Berl). 2012;90:1079-89. 